\title{
Criterion validity of the Motor Coordination and Dexterity Assessment - MCDA for 7 - and 8-years old children
}

\author{
Análise da validade de critério da Avaliação da Coordenação e Destreza Motora \\ - ACOORDEM para crianças de 7 e 8 anos de idade
}

Ana A. Cardoso', Lívia C. Magalhães²

\begin{abstract}
Background: Developmental Coordination Disorder (DCD) is characterized by impaired development of motor coordination, with impact on daily life activities and academic performance. The Motor Coordination and Dexterity Assessment (MCDA) was created to offer Brazilian rehabilitation professionals a valid and reliable instrument for detecting DCD. Objective: To examine the MCDA criterion validity. Methods: One hundred and eighty one children aged 7 and 8 years from the metropolitan region of Belo Horizonte, MG, Brazil, pre-selected using the Developmental Coordination Disorder Questionnaire (DCDQ-Brazil), were evaluated with the MCDA and the Movement Assessment Battery for Children (MABC-II). Concurrent validity was assessed using Spearman correlation index and the predictive validity was calculated using sensitivity, specificity, positive and negative predictive values. ROC curves were constructed to determine the optimal cutoff point of MCDA. Results: Spearman correlation between the total scores of MCDA and MABC-II at 7 and 8 years were $0.596(p=0.000)$ and $0.730(p=0.000)$, respectively. The cutoff points defined by the ROC curves approached the $40^{\text {th }}$ percentile, corresponding to a sensitivity of 0.91 and 0.74 and specificity of 0.74 and 0.90 for children 7 and 8 years old, respectively. Conclusion: The results indicate moderate values of concurrent and predictive validity of the MCDA. Future studies should reexamine the cutoff points of the MCDA in other random samples, representative of Brazilian children 4 to 8 years of age. The predictive validity of the full instrument for DCD should be re-examined in well defined clinical samples.
\end{abstract}

Keywords: motor skills disorder; validity; assessment; movement; rehabilitation.

\section{Resumo}

Contextualização: O Transtorno do Desenvolvimento da Coordenação (TDC) se caracteriza por prejuízo no desenvolvimento da coordenação motora, com impacto nas atividades de vida diária e desempenho acadêmico. A Avaliação da Coordenação e Destreza Motora (ACOORDEM) vem sendo criada para oferecer aos profissionais de reabilitação brasileiros instrumentação confiável e válida para detecção do TDC. Objetivo: Examinar a validade de critério da ACOORDEM. Métodos: Cento e oitenta e uma crianças de 7 e 8 anos da região metropolitana de Belo Horizonte,MG, pré-selecionadas pelo Developmental Coordination Disorder Questionnaire (DCDQ-Brasil), foram avaliadas com a ACOORDEM e com o Movement Assessment Battery for Children (MABC-II). A validade concorrente foi avaliada pelo índice de Correlação de Spearman e a validade preditiva, pelos valores de sensibilidade (S), especificidade (E), valor de predição positivo (VPP) e valor de predição negativo (VPN). Curvas ROC foram realizadas para determinar o ponto de corte ótimo da ACOORDEM. Resultados: A Correlação de Spearman entre os escores totais da ACOORDEM e do MABC-II foi de 0,596 ( $p=0,000)$ aos 7 e 0,730 ( $p=0,000)$ aos 8 anos. O ponto de corte da ACOORDEM definido pelas curvas ROC se aproximou do percentil 40, o que corresponde a S de 0,91 e 0,74 e E de 0,74 e 0,90 aos 7 e 8 anos, respectivamente. Conclusão: Resultados apontam valores moderados de validade concorrente e preditiva da ACOORDEM. Estudos futuros devem reexaminar os pontos de corte da ACOORDEM em amostra aleatória, representativa de crianças brasileiras de 4 a 8 anos de idade. A validade preditiva para TDC do instrumento completo deve ser reexaminada em amostras clínicas bem definidas.

Palavras-chave: transtorno das habilidades motoras; validade dos testes; avaliação; movimento; reabilitação.

Received: 03/09/2011 - Revised: 05/31/2011 - Accepted: 09/26/2011

${ }^{1}$ Department of Occupational Therapy, Universidade Federal do Paraná (UFPR), Curitiba, PR, Brazil

${ }^{2}$ Department of Occupational Therapy, Universidade Federal de Minas Gerais (UFMG), Belo Horizonte, MG, Brazil

Correspondence to: Ana Amélia Cardoso, Av. Lothário Meissner, n 632, Setor de Ciências da Saúde, Bloco Didático 2, Depto de Terapia Ocupacional, Jardim Botânico, CEP 80210-170,

Curitiba, PR, Brasil, e-mail: anaameliacardoso@gmail.com ou anaameliato@ufpr.br 


\section{Introduction $: \therefore$.}

There are many controversies regarding the evaluation of children with Developmental Coordination Disorder (DCD), and currently no gold standard to detect this health condition is available ${ }^{1,2}$. DCD is characterized by a notable impairment in the development of motor coordination that is not explained by mental reatardation or by any known physical disorder ${ }^{3}$. The diagnosis of the condition is made only when the motor impairment interferes significantly with individuals daily living routines or their academic performance ${ }^{3}$.

It is important to identify DCD as soon as possible, because of its negative impact on the activities and participation of children ${ }^{4}$ that leads to long term consequences. Although the estimated DCD prevalence in school-age children is around $6 \% 5,6$, few children in Brazil are diagnosed with the condition due to the fact that commonly used diagnostic tests, such as the Movement Assessment Battery for Children (MABC-II) ${ }^{7}$ and Bruininks-Oseretsky Test of Motor Proficiency (BOTMP-2), are not validated for Brazilian children. Seeking to offer Brazilian professionals who work with children, a reliable, valid, easy to apply and low cost instrument for the detection of DCD in children from 4 to 8 years, Magalhães, Nascimento and Rezende ${ }^{9}$ developed the Motor Coordination and Dexterity Assessment (MCDA).

The MCDA was developed and is being tested according to the guidelines by Benson and Clark ${ }^{10}$, including phases of (I) planning, (II) construction, (III) quantitative evaluation of items and (IV) validation. All phases of development have been completed step by step. In agreement with the perspectives of the International Classification of Functioning, Disability and Health (ICF $)^{11}$, the test consists of traditional items for observation of motor performance (body function and activity) and of questionnaires for parents and teachers concerning participation in daily life activities. In the quantitative evaluation phase of the test development, items of different areas of the test were examined separately ${ }^{12-15}$, allowing the identification and retainment of items with good reliability (test-retest and interexaminers) and that also demonstrated good validity to differentiate motor performance by age. Although the psychometric properties of all items have been evaluated, the test was not applied in full; and therefore, the total score was not calculated and selected items were not evaluated for its usefullness to differentiate motor skills of children with and without DCD.

The objectives of the present study was to investigate the criterion validity of the $\mathrm{MCDA}$, using the $\mathrm{MABC}-\mathrm{II}^{7}$ as reference standard, which is the most commonly reported instrument in the literature for the detection of $\mathrm{DCD}^{16}$. Criterion validity is the most practical and objective form of validation that evaluates the ability of a test to predict results obtained from an external criteria ${ }^{17}$. There are two types of criterion validity: the concurrent validity, that compares the test of interest with a gold or reference standard and is usually calculated using correlation coefficients, and the predictive validity, that evaluates the ability of the test to predict an outcome and is usually tested using sensibility (S), specificity (E), positive predictive value (PPV) and negative predictive value (NPV) ${ }^{18}$.

In the present study, predictive validity was operationally defined as the capacity of the MCDA to predict children's diagnosis (DCD or non-DCD), based on the MABC-II score ${ }^{7}$. Concurrent validity was defined by the correlation between the scores of the two tests. An additional aim of the study was to estimate preliminary cutoff points for the MCDA to facilitate investigation of the clinical usefulness of the instrument in future studies.

\section{Methods : :}

\section{Participants}

One hundred and eighty one children aged 7 and 8 yrs from the metropolitan region of Belo Horizonte, MG, Brazil, divided into two groups participated in the study:

- Group 1: children with DCD signs, classified based on the Developmental Coordination Disorder Questionnaire - Brazilian version (DCDQ-Brazil) ${ }^{19}$. Inclusion criteria: in the absence of Brazilian standards, scores below the cutoff point of the Canadian $\mathrm{DCDQ}^{20}$ were used as criteria. Fifteen children aged $7 \mathrm{yrs}$ and 22 children aged 8 yrs from private schools and 27 children aged 7 yrs and 27 children aged 8 yrs from public schools were recruited, totaling 91 children with probable DCD.

- Group 2: typical children, without complaints of motor impairments, paired by gender and age with each child with probable DCD. The pairs were recruited among the classmates of the children from group 1, based on the DCDQBrazil score above the cutoff of $\mathrm{DCDQ}^{20}$. Fifteen children aged 7 yrs and 23 children aged 8 yrs from private schools and 28 children aged 7 yrs and 24 children aged 8 yrs from public schools were recruited, totaling 90 children without signs of motor impairments.

The DCDQ-Brazil ${ }^{19}$ was responded by the parents of 793 children in order to obtain the sample of 181 children with and without signs of motor impairments. In both groups, children who showed the following signs were excluded: (a) physical deficits, neurological alterations or clinical diagnosis of diseases such as cerebral palsy, autism and muscular dystrophy; (b) hearing and/or vision impairment; (c) cognitive deficit; (d) orthopedic impairments or fracture of lower limbs up to six 
months before the evaluation date and (e) diagnosis of genetic disease. In group 2, children with the following signs were also excluded: (a) prematurity history (gestational age $\leq 36$ weeks) and/or low birth weight (below $2500 \mathrm{~g}$ ); (b) poor school performance with grade repetition and (c) need for any type of motor therapy (ex: occupational therapy, physical therapy, psychomotor). Parents/guardian of each child signed the informed consent term, authorizing the participation in the study.

\section{Instrumentation}

- $\mathrm{MCDA}^{21}$ : The test aims to identify children from 4 to 8 yrs-old with DCD. The current version of this instrument was developed using validity testing of its items, and therefore, includes only items that showed good reliability (i.e., test-retest and inter-examiners) and performance discrimination by age. In the present study, only the motor performance observed items were examined. These items were distributed into two subscales: (a) coordination and manual dexterity, with 16 items and (b) bilateral coordination and motor planning, with 26 items. The test time was approximately 60 minutes.

- DCDQ-Brazil ${ }^{19}$ : Brazilian version of the $\mathrm{DCDQ}^{20}$. It is a parent questionnaire translated and adapted for Brazilian children, that is answered by parents and was developed in Canada to screen children from 5 to 15 yrs-old with DCD $^{19}$. There is evidence of good test-retest reliability and construct validity from different countries ${ }^{19,22}$. The questionnaire items are scored in a four-point scale, that sum to a total score. Scores below 47 at age 7 and below 56 at age 8 indicate children who may have $\mathrm{DCD}^{20}$.

- MABC-II?: is a standardized British test used for screening, identification and description of motor performance impairments in children from 3 to 16 yrs-old. It includes gross and fine motor tasks, grouped into three categories: manual dexterity (three items), throwing and catching (two items), and balance (three items). The raw scores are converted into percentiles, and scores $\leq$ the $5^{\text {th }}$ percentile are indicative of DCD; $6^{\text {th }}$ to $15^{\text {th }}$ percentiles indicate risk/suspicion of DCD and above 16, normal motor performance ${ }^{7}$. MABC-II can be applied in 20 minutes and the test has been reported to have good validity and reliability?

\section{Procedures}

Six public schools and 56 private schools of basic education of Belo Horizonte, MG, Brazil, were contacted, totaling 62 contacted schools. Among them, six (100\%) of the public schools and 21 (37.5\%) of the private schools agreed to participate. The informed consent with information on the objectives of the study, the DCDQ-Brazil ${ }^{19}$ and a short questionnaire about birth conditions and the child's developmental history were sent to parents and/or guardians of children. During participants' selection, 1879 children received the questionnaires, but only 793 $(42.2 \%)$ returned it fully filled and with the informed consent term signed.

Based on the scores of the returned questionnaires, one Scientific Initiation (SI) student identified children with probable DCD diagnosis. For each child detected with DCD signs, another child from the same classroom without signs of motor impairment, matched by age and gender was selected. The process of the children's matching was conducted by the SI student, so that the examiner was blinded to the probable diagnosis of the child's motor performance.

All children selected based on the DCDQ-Brazil were evaluated using the $\mathrm{MCDA}^{21}$ and the MABC-II ${ }^{7}$ at their own school, in schedules defined by the teachers and that did not affect important pedagogic activities. Evaluations were conducted by an occupational therapists with experience with children with DCD. Assessments were divided into two sessions; on the first, the MABC-II was applied and on the second, the MCDA. The study was approved by the Ethics in Research Committee (COEP) of the Universidade Federal de Minas Gerais (UFMG), Belo Horizonte, MG, Brazil (protocol ETIC 80/08).

\section{Data analysis}

The statistical package SPSS version 17.0 was used. Initially the raw score for each MCDA's item was converted into z score, and each point was subtracted from the mean of the item and divided by the standard-deviation. The quartiles of the $\mathrm{z}$ scores for each item of the MCDA was calculated, providing standardized scores for each item, ranging from 1 to 4 . Standardized scores were added, resulting in three scores for analysis for each child: (a) manual coordination and dexterity; (b) bilateral coordination and motor planning and (c) total score of the test.

Spearman Correlation Coefficient between the standardized total scores and the subscales of the MABC-II and the MCDA, for both age groups, was analyzed for the calculation of concurrent validity, with significance level of 0.05 . Correlation coefficient equal or above 0.70 indicates that the performance in one test may predict performance in the other test ${ }^{18}$.

For calculation of the predictive validity, the values of sensitivity, specificity, positive predictive values (PPV) and negative predictive values (NPV) were calculated according to Portney and Watkins ${ }^{17}$. Sensitivity is the probability of obtaining a correct positive result in patients who have the target condition. Specificity is the probability of a correct negative test in the individuals who do not have the target condition. PPV estimates 
the probability of a person that has the condition to be correctly diagnosed. A test with high PPV will provide a strong estimate of the real number of patients who have the target condition. On the other hand, PNV indicates the probability of a person who does not have the condition to have a negative test. A test with high PNV will provide a strong estimate of the number of people who do not have the target condition ${ }^{17}$. Preferential values for the indices of predictive validity are: 0.80 for sensitivity, 0.90 for specificity, 0.70 for PPV and $\mathrm{PNV}^{23}$.

Sensitivity, specificity and PPV and PNV were calculated between the MCDA scores, with cutoff points at percentile 5 and 15 , to determine which cutoff point had the best potential to predict DCD, as identified by the MABC-II. Percentile 5 was used because it is the value defined by consensus among professionals and researchers who work with $\mathrm{DCD}^{24}$, in addition to being the cutoff point recommended in the MABC-II manual ${ }^{7}$. Percentile 15 was used in previously published studies of concurrent and predictive validities of other instruments with the MABC-II ${ }^{25,26}$.

Using the MABC-II as reference standard, the optimal cutoff point, based on the highest sensitivity and specificity values for the scores of the two MCDA subareas and the total score of MCDA, were estimated through Receiver Operating Characteristic Curve (ROC curve), with significance level of 5\%. The ROC curve was constructed using the MedCalc software. The percentile corresponding to the scores defined by ROC curves was identified.

\section{Results $: \because$.}

The sample characteristics divided by age and type of school are shown in Table 1.

After the conversion of the raw scores into standardized scores, the maximum possible point for the total score of the MCDA was 196, with subscore of 76 for the manual coordination and dexterity scale and of 120 for the bilateral coordination and motor planning scale. The maximum scores reached by $7 \mathrm{yr}$-old children were 165 for the total score, 66 for manual coordination and dexterity and 104 points for bilateral coordination and motor planning. For 8 yr-old children, the obtained maximum scores were, 179, 70 and 109 respectively. Mean standardized scores by age and school type are shown in the Table 1.

Considering the percentile 5 of the $\mathrm{MABC}-\mathrm{II}^{7}$ as the reference standard, the DCD frequency was $25.3 \%$ among 7 yr-old children and $21.1 \%$ among 8 yr-old children. Spearman Correlations Coefficient between the scores of MABC-II and MCDA are shown in Table 2. Table 3 presents the values of sensitivity, specificity, PPV and PNV for the percentiles 5 and 15 of the MCDA.

Figures 1 and 2 show the ROC curves for the MCDA total score for children aged 7 and 8 yrs, respectively.

According to the ROC curves, the most appropriate cutoff point for the MCDA total score for 7 and 8 years children would be 117 and 125, respectively. Such values correspond to the percentiles 42 and 23, respectively. Considering the scores of manual coordination and dexterity scale, the most appropriate cutoff point, according to the ROC curve, would be 42 points $\left(38^{\text {th }}\right.$ percentile) for 7 year old children and 46 points $\left(43^{\text {rd }}\right.$ percentile) for 8 years old children. For bilateral coordination and motor planning scale, at 7 years, the most appropriate cutoff point would be 71 points ( $33^{\text {rd }}$ percentile), while at 8 years, the most suitable would be 88 points ( $47^{\text {th }}$ percentile). Table 3 shows the predictive validity indices at the cutoff points defined on the ROC curves.

\section{Discussion $: \because$.}

The present study investigated the criterion validity of the $\mathrm{MCDA}^{1}$, using the MABC-II ${ }^{7}$ as a reference standard. The results indicated preliminary cutoff points for the test in terms of standardized scores, that may be used in future studies. As the first integral application of the MCDA, the results were promising, because the calculation of the standardized total score provided positive information on the characteristics of the items group and, at the same time, indicated possible limitations of the test, that should be verified before releasing the instrument for clinical use.

Table 1. Sample characteristics and MCDA performance mean ( \pm standard deviation).

\begin{tabular}{|c|c|c|c|c|}
\hline & 7 Years-old public school & 7 years-old private school & 8 Years-old public school & 8 years-old private school \\
\hline $\mathrm{N}$ & 55 & 30 & 51 & 45 \\
\hline Female & $21(38.2 \%)$ & $10(33.3 \%)$ & $32(62.7 \%)$ & $20(44.4 \%)$ \\
\hline Male & $34(61.8 \%)$ & $20(66.7 \%)$ & $19(37.3 \%)$ & $25(55.6 \%)$ \\
\hline Age (months) & $86.93 \pm 2.88$ & $89.13 \pm 2.86$ & $99.94 \pm 4.00$ & $101.82 \pm 3.29$ \\
\hline Total MCDA score* & $117.56 \pm 21.71$ & $125.83 \pm 19.60$ & $134.84 \pm 16.44$ & $136.67 \pm 21.11$ \\
\hline Manual Coordination and Dexterity* & $43.25 \pm 11.02$ & $47.20 \pm 10.48$ & $47.27 \pm 8.51$ & $49.59 \pm 9.98$ \\
\hline $\begin{array}{l}\text { Bilateral Coordination and } \\
\text { motor planning* }\end{array}$ & $74.31 \pm 12.76$ & $78.63 \pm 12.68$ & $87.56 \pm 10.19$ & $87.08 \pm 13.09$ \\
\hline
\end{tabular}

* Standard Score. 
Table 2. Correlation between total and area scores of the MABC- II and the MCDA.

\begin{tabular}{|c|c|c|c|c|c|c|}
\hline & $\begin{array}{c}\text { Total Score } \\
\text { MABC-II }\end{array}$ & Total MCDA & $\begin{array}{c}\text { Manual Coordina- } \\
\text { tion and Dexterity } \\
\text { - MCDA }\end{array}$ & $\begin{array}{l}\text { Bilateral Coordination } \\
\text { and motor planning - } \\
\text { MCDA }\end{array}$ & $\begin{array}{c}\text { Manual Dexterity } \\
\text { - MABC-II }\end{array}$ & $\begin{array}{c}\text { Aiming and } \\
\text { Catching - } \\
\text { MABC-II }\end{array}$ \\
\hline \multicolumn{7}{|l|}{7 years-old } \\
\hline Total score - MCDA & $0.596^{\star \star}$ & & & & & \\
\hline Manual Coord. - MCDA & $0.538^{\star \star}$ & $0.879^{\star \star}$ & & & & \\
\hline Bilateral Coord. - MCDA & $0.538^{\star \star}$ & $0.894^{\star \star}$ & $0.591^{\star \star}$ & & & \\
\hline Manual Dexterity - MABC-II & $0.752^{\star \star}$ & $0.557^{\star \star}$ & $0.560^{\star \star}$ & $0.454^{\star *}$ & & \\
\hline Aiming/catching - MABC-II & $0.690^{* *}$ & $0.318^{\star *}$ & $0.231^{*}$ & $0.349^{\star *}$ & $0.392^{\star *}$ & \\
\hline Balance - MABC-II & $0.819^{\star \star}$ & $0.517^{\star \star}$ & $0.456^{\star \star}$ & $0.480^{\star *}$ & $0.398^{\star \star}$ & $0.409^{\star \star}$ \\
\hline \multicolumn{7}{|l|}{8 years-old } \\
\hline Total score - MCDA & $0.730^{\star *}$ & & & & & \\
\hline Manual Coord. - MCDA & $0.550^{\star \star}$ & $0.858^{\star \star}$ & & & & \\
\hline Bilateral Coord. - MCDA & $0.713^{\star \star}$ & $0.873^{\star \star}$ & $0.525^{\star \star}$ & & & \\
\hline Manual Dexterity - MABC-II & $0.753^{\star \star}$ & $0.622^{\star \star}$ & $0.528^{\star \star}$ & $0.559^{\star \star}$ & & \\
\hline Aiming/catching - MABC-II & $0.676^{\star \star}$ & $0.515^{\star \star}$ & $0.313^{\star \star}$ & $0.557^{\star \star}$ & $0.286^{\star \star}$ & \\
\hline Balance - MABC-II & $0.801^{\star \star}$ & $0.582^{\star \star}$ & $0.467^{\star \star}$ & $0.555^{\star \star}$ & $0.435^{\star \star}$ & $0.378^{\star \star}$ \\
\hline
\end{tabular}

${ }^{*}$ significant correlation $p>0.05$; ${ }^{* *}$ significant correlation $p>0.01$.

Table 3. Sensitivity, specificity, positive predictive values and negative predictive values of different MCDA cut-off points.

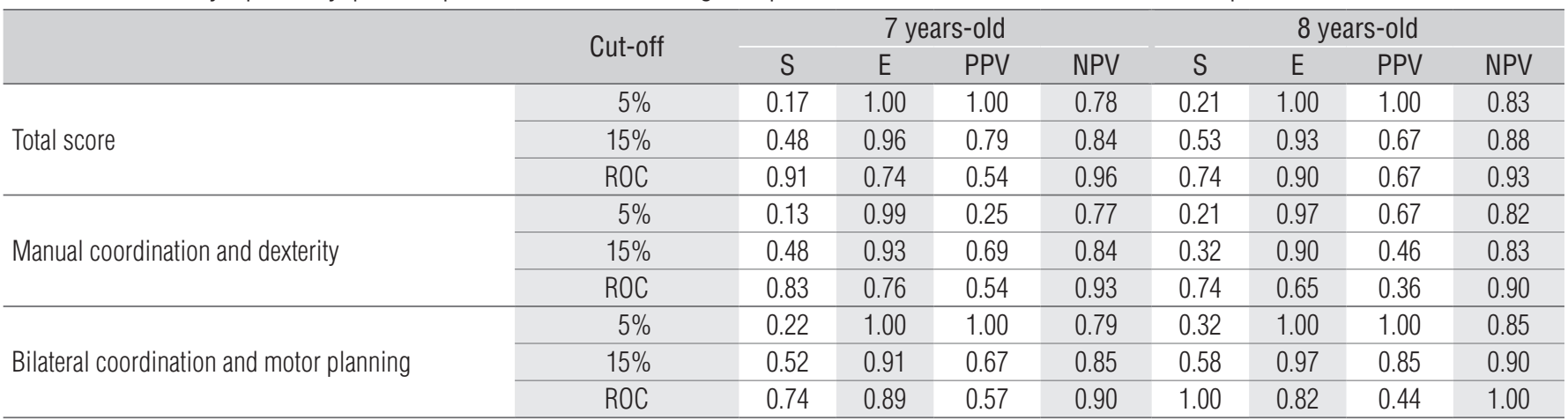

S=Sensitivity; E=specificity; PPV=positive predictive value; NPV=negative predictive value, ROC=best cut-off point defined by ROC curves.

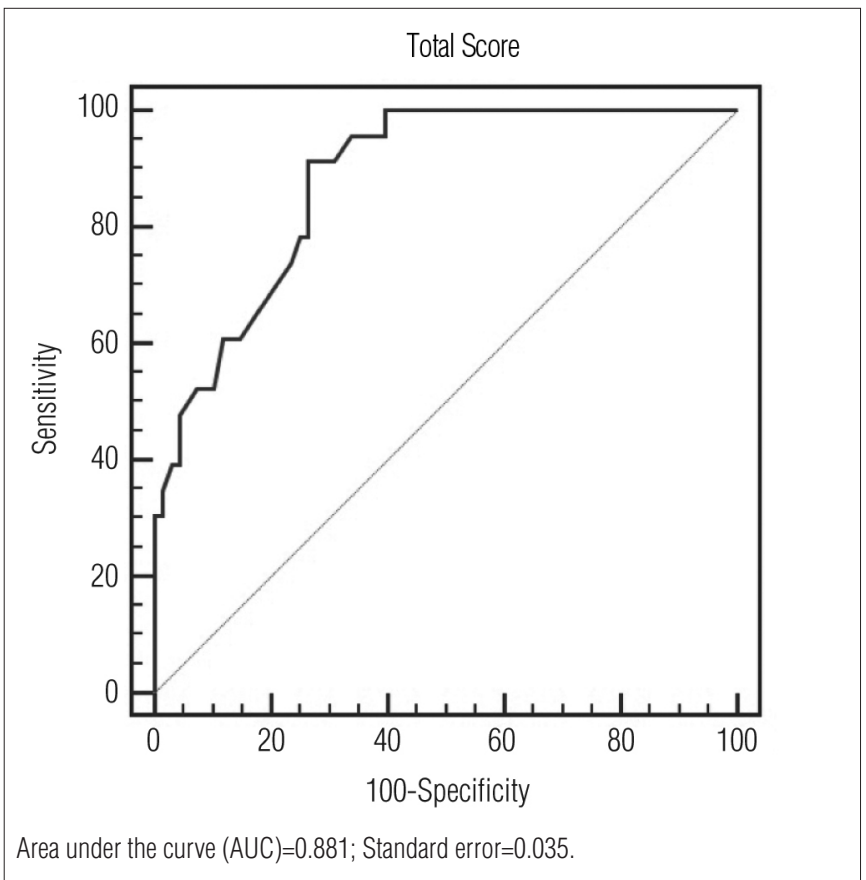

Figure 1. MCDA total score's ROC Curve of 7-year-old children.

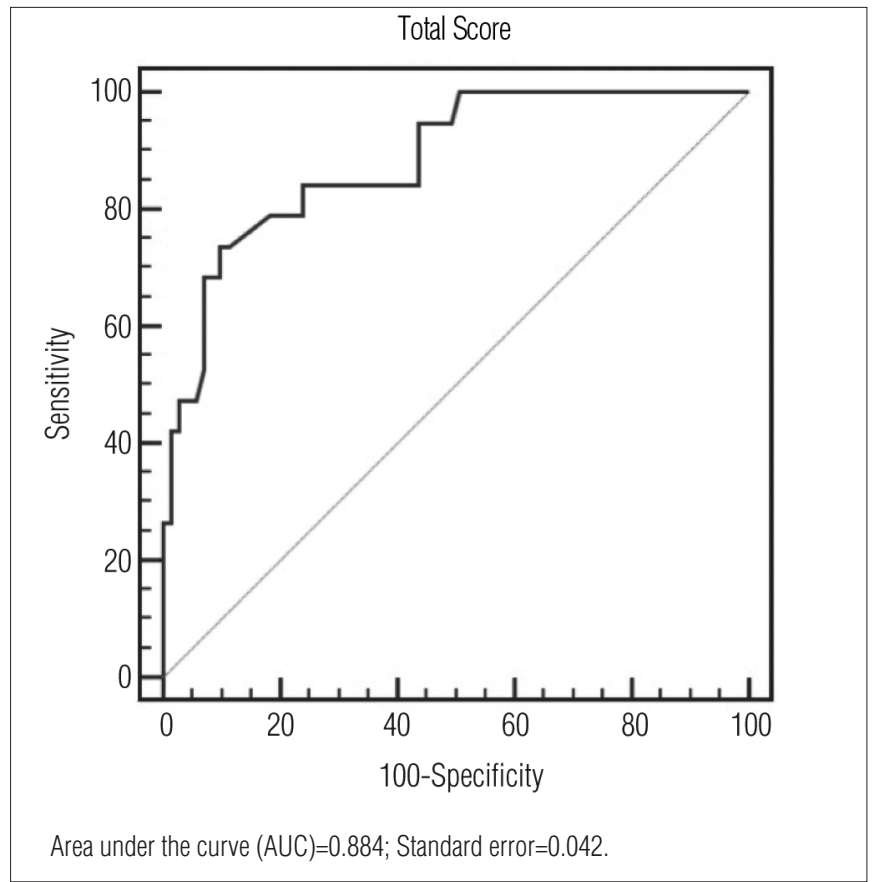

Figure 2. MCDA total score's ROC Curve of 8-year-old children. 
The prevalence of DCD in the sample raises attention $25.3 \%$ at 7 years and $21.1 \%$ at 8 years - which was much higher than the prevalence reported in the literature, estimated around 5 to $8 \%$ of the school- age children ${ }^{4-6}$. This result was expected, because the sample was purposely pre-selected using the DCDQ-Brazil ${ }^{19}$, aiming to obtain two groups of children, with and without DCD signs.

Regarding the main objective of the study, when examining the effects of the different cutoff points on the predictive validity indices (Table 3), it may be observed that the percentiles 5 and 15 are inadequate due to the fact that the sample contains more than $20 \%$ of children with DCD signs. When the cutoff points defined by the ROC curves are used, the indices reach moderate values and some reach the preferential levels described for predictive validity. It still may be observed that the percentiles corresponding to the cutoff points are very high, even considering a sample with over-representation of children with motor impairments.

The fact that, even setting the cutoff point of MCDA around the percentile 40, as suggested by the ROC curves (Table 3), it still does not identify all children with delay, suggesting that some test items may be too easy to respond or are of little discriminatory value for the sample. Although Cardoso ${ }^{27}$ has reported that most of the MCDA items differentiate the performance of children with and without DCD, the difficulty level should be analyzed to eliminate too easy items, which do not collaborate for an accurate identification of motor impairments.

The moderate indices of concurrent validity are compatible with those reported by other authors, such as Croce, Horvat and McCarthy ${ }^{28}$, who reported correlations ranging from 0.60 to 0.79 between the MABC and the BOTMP tests for children from 5 to 10 years. Recently, Spironello et al. ${ }^{26}$ observed lower correlation (0.50) between the BOTMP-II and the MABC-II. Smits-Engelsman, Henderson and Michels ${ }^{29}$ reported correlations ranging from 0.28 to 0.62 between the MABC and the KTK motor test. These same variations may be observed in Table 2 and, as expected, there was higher correlation between subscales of the same test and lower correlation between items related to gross and fine motor coordination, such as catching balls and manual dexterity.

Table 2 shows that there is a good concurrent validity between the total score of MABC-II and MCDA, as well as between a greater numbers of subtests at 8 yrs of age. At 7 yrs of age the correlations are lower, possibly because the MCDA tasks are a little more difficult for this age group.

Several factors might have contributed to the moderate indices of concurrent validity. As moderate correlations indicate that the two instruments do not measure exactly the same motor skills, the MCDA and the MABC-II possibly do not identify the same children as having motor impairments. Incongruence among different motors tests in the identification of DCD has already been discussed by some authors. Crawford,
Wilson and Dewey ${ }^{25}$ reported that the consistency among the MABC, the BOTMP and the DCDQ was below $80 \%$. Spironello et al. $^{26}$ reported Kappa values that range from 0.19 to 0.29 between the short/triage form of the BOTMP and the MABC. In other words, both instruments have different characteristics, that influence the identification of motor impairments. These data alert for the fact that scores of motor tests are not definitive. For the diagnosis of DCD, information of multiple sources should be included, especially when considering performance of functional activities in daily life activity contexts.

Another factor that might have contributed to the moderate values of concurrent validity is the fact that the MABC-II has not been validated for Brazilian children. This is a limitation of the study, however this instrument was chosen as reference standard for being the most mentioned in the literature in studies of concurrent validity ${ }^{16}$. The MABC-II ${ }^{7}$ is still not widely used in Brazil, but in a study conducted in the northern Brazilian region, Souza et $\mathrm{al}^{30}$ concluded that the $\mathrm{MABC}^{31}$, previous version of the test, does not need modification to be used with children of different environments. Despite the fact that the tasks of the test are simple and that the MABC has evidence for validity in several countries ${ }^{29,32,33}$, sice there are no normative values for Brazilian children, one cannot affirm that the score corresponding to the percentile 5, cutoff point for DCD, is the same in Brazilian and British populations. Future studies, with representative random samples of Brazilian children from different age groups, should investigate the validity of the cutoff points for both MCDA and MABC-II.

The present data support the use of the MCDA total score to characterize the motor performance of Brazilian children with 7 and 8 yrs of age, however the cutoff points used for the identification of delay need to be better defined. The present study indicated that the use of different cutoff points of the MCDA result in a variable number of children correctly identified with DCD. Possibly the MCDA diagnostic accuracy could be improved with the combined analysis of motor items and data obtained in the parents and teachers' questionnaires, which will be examined in future studies.

\section{Conclusion $: \therefore$.}

Validation of assessment instruments is a continuous process $^{34}$ and in the present study, the validity of the MCDA scores was examined in relation to an external criteria, the MABC-II. The moderate indices of concurrent validity resemble those of other motor performance tests reported in the literature ${ }^{28,29}$. The predictive validity indices indicate a high cutoff point for MCDA, suggesting the possibility that some items may have little discriminatory ability or are easy for children. Future studies should examine this hypothesis and items could potentially be eliminated. 
The data reported highlight the complexity of the identification of disorders such as DCD, that have a diagnosis that is primarily clinical. Although it is essential to use standardized and validated motor tests, information of several sources is necessary, involving interdisciplinary efforts. In future studies, the information gathered with direct observation and the MCDA questionnaire should be combined; cut-off points should be reexamined in random samples, but clinical samples, with confirmed diagnosis, should also be included to verify the clinical usefulness of the test for identification of DCD in Brazilian children.

\section{Acknowledgment : : :}

To all the schools and parents who allowed the children's participation in the study; to the technical assistance and scientific initiation grant holders for the collaboration in the recruitment of schools, children selection and data collection; to the Conselho Nacional de Desenvolvimento Cientifico e Tecnológico (CNPq) and to the Fundação de Amparo a Pesquisa do Estado de Minas Gerais (FAPEMIG), for funding the MCDA project.

\section{References}

$-\circ$

1. Geuze RH, Jongmans MJ, Schoemaker MM, Smits-Engelsman BC. Clinical and research diagnostic criteria for developmental coordination disorder: a review and discussion. Hum Mov Sci. 2001;20(1-2):7-47.

2. Kirby A, Sugden DA. Children with developmental coordination disorders. J R Soc Med. 2007;100(4):182-6.

3. American Psychiatric Association. Manual diagnóstico e estatístico de transtornos mentais: DSM-IV-TR tm - texto revisado. $4^{\mathrm{a}}$ ed. Porto Alegre: Artmed; 2002.

4. Magalhães LC, Cardoso AA, Missiuna C. Activities and participation in children with developmental coordination disorder: a systematic review. Res Dev Disabil. 2011;32(4):1309-16.

5. Cairney J, Hay JA, Faught BE, Corna LM, Flouris AD. Developmental coordination disorder, age and play: a test of the divergence in activity-deficit with age hypothesis. Adapt Phys Activ $Q$. 2006;23:261-76

6. Dewey D, Wilson BN. Developmental coordination disorder: what is it? Phys Occup Ther Pediatr. 2001;20(2-3):5-27.

7. Henderson SE, Sugden DA, Barnett AL. Movement Assessment Battery For Children. $2^{\text {nd }}$ ed. Londres: The Psychological Corporation; 2007

8. Bruininks RH, Bruininks BD. Bruininks-Oseretsky Test of Motor Proficiency. $2^{\text {nd }}$ edition. Circle Pine: American Guidance Service; 2005.

9. Magalhães LC, Nascimento VCS, Rezende MB. Avaliação da coordenação e destreza motora ACOORDEM: Etapas de criação e perspectivas de validação. Rev Ter Ocup. 2004;15(1):17-25.

10. Benson J, Clark F. A guide for instrument development and validation. Am J Occup Ther. 1982;36(12):789-800

11. Organização Mundial de Saúde CIF: Classificação Internacional de Funcionalidade, Incapacidade e Saúde. São Paulo: Editora da Universidade de São Paulo - EDUSP; 2003.

12. Cury RLM, Magalhães LC. Criação de protocolo de avaliação do equilíbrio corporal em crianças de quatro, seis e oito anos de idade: uma perspectiva funcional. Rev Bras Fisioter. 2006;10(3):346-53.

13. Cardoso AA, Magalhães LdeC. Bilateral coordination and motor sequencing in Brazilian children: preliminary construct validity and reliability analysis. Occup Ther Int. 2009;16(2):107-21.

14. Cardoso AA, Galvão BAP, Magalhães LC. Fine motor coordination and manual dexterity of the Assessment of Motor Coordination and Dexterity (AMCD). Santiago: Congress 2010 Abstract WFOT 2010. 2010;1744.

15. Lacerda TTB, Magalhães LC, Rezende MB. Validade de conteúdo de questionários de coordenação motora para pais e professores. Rev Ter Ocup. 2007;18(2):63-77.

16. Cairney J, Hay J, Veldhuizen S, Missiuna C, Faught BE. Comparing probable case identification of developmental coordination disorder using the short form of the Bruininks-Oseretsky Test of Motor Proficiency and the Movement ABC. Child Care Health Dev. 2009;35(3):402-8.

17. Portney LG, Watkins MP. Foundations of clinical research - applications to practice. $3^{\text {rd }}$ ed. Upper Saddle River: Pearson Prentice Hall; 2009

18. Richardson PK. Use of standardized tests in pediatric practice. In: Case-Smith J. Occupational Therapy for Children. $5^{\text {th }}$ ed. St Louis: Elsevier Mosby; 2005. p. 246-275.
19. Prado MS. Tradução e adaptação cultural do Developmental Coordination Disorder Questionnaire (DCDQ). [dissertação]. Programa de Mestrado em Ciências da Reabilitação, Escola de Educação Física, Fisioterapia e Terapia Ocupacional, Universidade Federal de Minas Gerais; 2007.

20. Wilson BN, Dewey D, Campbell a. Developmental coordination disorder questionnaire (DCDQ) Calgary: Alberta Children's Hospital Research Center; 1998.

21. Magalhães LC, Rezende MB, Cardoso AA. Avaliação da Coordenação e Destreza Motora ACOORDEM - Versão 2. Manuscrito não publicado - Departamento de Terapia Ocupacional UFMG; 2008

22. Loh PR, Piek JP, Barrett NC. The use of the developmental coordination disorder questionnaire in Australian children. Adapt Phys Activ Q. 2009;26(1):38-53.

23. Schoemaker MM, Flapper B, Verheij NP, Wilson BN, Reinders-Messelink HA, de Kloet A Evaluation of the Developmental Coordination Disorder Questionnaire (DCDQ) as a screening instrument. Dev Med Child Neurol. 2006;48(8):668-73

24. Sugden DA. Leeds Consensus Statement: Developmental Coordination Disorder as a Specific Learning Disorder. ESCR Seminar Series; 2006

25. Crawford SG, Wilson BN, Dewey D. Identifying developmental coordination disorder: consistency between tests. Phys Occup Ther Pediatr. 2001;20(2-3):29-50.

26. Spironello C, Hay J, Missiuna C, Faught BE, Cairney J. Concurrent and construct validation of the shor form of the Bruininks-Oseretsky Test of Motor Proficiency and the Movement-ABC when administered under field conditions: implications for screening. Child Care Health Dev. 2010;36(4):499-507.

27. Cardoso AA. Validade concorrente e preditiva da Avaliação da Coordenação e Destreza Motora ACOORDEM [tese]. Belo Horizonte, MG: Programa de Doutorado em Ciências da Reabilitação, Escola de Educação Física, Fisioterapia e Terapia Ocupacional, Universidade Federal de Minas Gerais; 2011.

28. Croce RV, Horvat M, McCarthy E. Reliability and concurrent validity of the movement assessment battery for children. Percept Mot Skills. 2001;93(1):275-80.

29. Smits-Engelsman BCM, Henderson SE, Michels CGJ. The assessment of children with Developmental Coordination Disorders in the Netherlands: The relationship between the Movement Assessment Battery for Children and the Körperkoordinations Test für Kinder. Hum Mov Sci. 1998;17(4-5):699-709.

30. Souza C, Ferreira L, Catuzzo MT, Corrêa UC. 0 teste ABC do Movimento em crianças de ambientes diferentes. Rev Port Cien Desp. 2007;7(1):36-47.

31. Henderson SE, Sugden DA. Movement Assessment Battery for Children. Londres: The Psychologica Corporation; 1992.

32. Chow SM, Henderson SE, Barnett AL. The Movement Assessment Battery for Children: a comparison of 4-year-old to 6-year-old children from Hong Kong and the United States. Am J Occup Ther. 2001;55(1):55-61.

33. Rösblad B, Gard L. The assessment of children with Developmental Coordination Disorders in Sweden: a preliminary investigation of the suitability of the movement ABC. Hum Mov Sci. 1998; 17(4-5):711-9.

34. Barnett AL. Motor Assessment in Developmental Coordination Disorder: from identification to intervention. International Journal of Disability, Development and Education. 2008;55(2):113-29. 